\title{
How IT Management Profile and IT Business Value Correlate - Exploring Cross-Domain Alignment
}

\author{
Anna Wiedemann \\ Neu-Ulm University \\ of Applied Sciences \\ anna.wiedemann@hs-neu-ulm.de
}

\author{
Heiko Gewald \\ Neu-Ulm University \\ of Applied Sciences \\ heiko.gewald@hs-neu-ulm.de
}

\author{
Andy Weeger \\ Neu-Ulm University \\ of Applied Sciences \\ andy.weeger@hs-neu-ulm.de
}

\begin{abstract}
Previous research hardly investigates how externally focused competitive strategies can be bridged with internal focused IT processes (i.e. crossdomain alignment). In view of this gap, we aim to shed light on the relationship between five archetypical IT management profiles and six IT business value domains that we derived from literature. Building on prior literature, we propose that each IT management profile delivers unique sources of value, thus, contributes to specific IT business value domains. In order to test our hypothesis, we conducted a quantitative matchedpair study across firms within the manufacturing industry. Our findings indicate that IT business value domains are linked to IT management approaches. The contribution of this paper is that we extent the existing theory of the contribution of the IT function. We present empirically findings that each IT management profile is associated with minimum one distinct IT business value domain.
\end{abstract}

\section{Introduction}

IT management deals with IT-business alignment on the strategic layer since more den 30 years and that issue has been extensively studied [3]. Until now, the issue of alignment is one of the major management topics for CIOs [1]. Furthermore, prior research has shown that IT-business alignment generates value for the company [5]. It is important, to understand alignment between business and IT objectives, but this process needs constant adjustments and improvements [1,7]. Additionally IT- business alignment [5] has been identified as key factor for realizing business value. Furthermore, research found out that aligned companies use more effectively IT to support business aims and take successfully market chances to achieve competitive advantage and excel firms profit [3].

Many -if not most- contemporary business processes are not conceivable without the support of adequate IT. Furthermore, in industries where products and business models are increasingly digitized, firms are not viable without IT [2, 12]. Consequently, spending on IT became a weighty part of corporate expenses [14], since the worldwide IT spending was \$3.5 trillion in 2015 [16].

Despite these developments, previous research has shown that investments in IT do not by default contribute to positive firm performance. Rather, measurable impacts of IT investments seems to be particularly dependent on a firm's ability to effectively manage the resource IT [17]. Additionally, the nature of the contribution of IT to firms' business value seems to be multi-layered (see e.g. [18]) and contingent on firm resources $[9,19]$. Hence, it is important to find out what are the essential contributions of IT to the rest of the organization.

Prior research particularly investigated the relationship between IT and business e.g. the role which IT played within the company and the impact on organizational performance [20]. Examining previous IT management approaches in order to pave the way to "a new theory of the contribution of the IT function in organizations", Guillemette and Pare [1] proposed a typology of ideal management profiles. The objective of this approach is to "provide a new conceptual and theoretical perspective on the role played by IT functions in organizations and on how such functions may evolve or transform over time" p.1 [21]. They provide descriptions and characteristics of five distinct and consistent ideal IT management profiles (ITMP) based on prior literature and empirical data and delivered the motivation for this research, because they provided further research opportunities in their paper. Each of these ITMP supplies a unique source of value to the company. 
We will present an overview of each ITMP in Table 1 in this paper.

In line with the argument that the value of IT is multi-layered [18], each ITMP is associated with an unique value contribution to the organization. Guillemette and Pare [1] further argue that IT functions which are close to any given ideal ITMP are most likely to outperform expectations. Considering the adoption of an ITMP, [1] confine their examination to CIOs interpretation of the centrality of IT to the organization as well as the perceptions of their influence and top-managements' IT knowledge.

However, further research for validation is needed to gain confidence in the findings of Guillemette and Pare [1]. Therefore, we follow the call of them [1] and carry out a quantitative survey to more deeply examine the contributions to the organization associated with the ITMP. We identified IT business value domains in literature to measure the commitment of IT management profiles and bring forward the following research question:

(RQ) Which IT management profiles contributes to which IT business value domains?

To approach these research questions, we first present our theoretical background and set up our hypotheses in the light of prior research. Subsequently, we empirically test the hypotheses by conducting a quantitative study. We examine the interrelations of ITMP and the IT functions contribution to the IT business value domains which we explain later in this paper. Further, we apply a correlation analysis. Our findings show that every ITMP is related to contribute to at least one IT business value domain. We close the paper with discussing our findings. We looked behind the research of Guillemette and Pare [1] and strengthened their approach with a quantitative study which they suggest. Our contribution is a research that presents implications for CIOs or IT managers which ITMP contribute to an IT business value domain. The limitations of this study and its implications for further research are presented in this paper as well.

\section{Theoretical background}

A review of the literature indicates that the phenomena of IT-business alignment is intensively discussed in case of strategic IT- business alignment. IT is still one of the most important concerns of CIOs and top level management $[22,23]$. Research on ITbusiness alignment demonstrates that the impact of IT on firm performance is dependent on the fit between the capabilities of IT and business needs [24].

Building on the argument of cross-domain alignment, it can be assumed that each of the ideal ITMP fits best to at least one IT business value domain. Below we briefly present the findings of our analysis of prior literature and, thereby, present the theoretical background for these propositions.

\subsection{Cross-domain alignment}

The research of Henderson and Venkatraman [25] describes the Strategic Alignment Model. With the help of this model, firms get impressions how they can align their strategies, infrastructure and processes. In their seminal work, [26] noted that IT and business need to be aligned on strategic and operational levels as well as across these levels. Although there is much research focusing on the strategic level [5], cross-domain alignment remains largely untouched by prior research. Cross-domain alignment focus on a holistic perspective of alignment with regard to strategy, process and infrastructure components from IT and business as well [3, 26]. Since changes in the business or IT strategy influences adoption at alignment between IT and business processes and infrastructure [3]. Crossdomain alignment is the fit between IT and business strategy, as well as among IT und business processes and infrastructure $[3,5,26]$. This type of alignment is

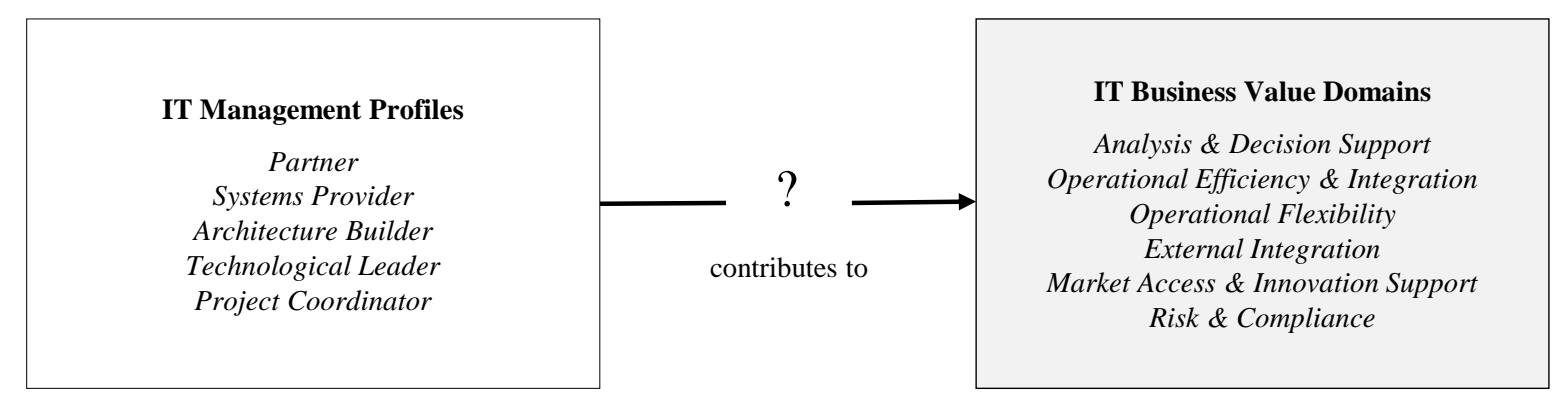

Figure 1. Research model 
important since a lot of changes take place in business or IT, and these changes need alignment in the affected domain $[3,27]$.

\subsection{IT management profiles}

Guillemette and Pare [1] conducted an extensive review of the literature and derived five archetypal ideal management profiles for IT functions in organizations, which they have named Partner, System Provider, Architecture Builder, Technological Leader, and Project Coordinator. Every profile has a theory base (see Table 1) and represent unique but compatible combinations of properties within the following dimensions: the critical activities of the IT function; the most important skills, knowledge and abilities for its employees; the nature of the relationship of IT function with business units and external partners; and the forms of IT governance models. These dimensions that are interdependent [21, 28], for example skills of IT functions employees will influences the scope of its tasks and activities. Each ideal profile is expected to provide a distinctive source of value (i.e. a specific contribution) to organizations (see Table 2. IT business value domains).

\subsection{IT business value domains}

Guillemette and Pare [1] identified five distinct dimensions in which IT may provide value to the firm. Moreover, they found that the contributions are contingent on the management profile adopted by IT, such as each ITMP primarily contributes to one dimension. To identify dimensions to which IT may contribute to, we conducted a comprehensive literature analysis starting with the review of [14] on IT business value. Schryen [14] performed a comprehensive literature review. On basis of this review we conducted a backward research by checking the articles cited within the paper. Moreover, we used Web of Science and Google Scholar to perform a forward search in order to identify articles that cited these articles. Afterwards we analyzed the identified papers. The research team developed rigor rules as guidelines for the coding and analyzing phase. As a result, a set of six distinct sources of value from IT were derived from literature. Table 2 visualizes and describes these six

\section{Table 1. Ideal IT management profiles based on [1]}

\begin{tabular}{|c|c|c|}
\hline IT management profile & Main characteristics & Proposed contribution \\
\hline Partner & $\begin{array}{l}\text {...aims to support business transformation } \\
\text { and fostering organizational innovation; } \\
\text { strong and ongoing presence in business; } \\
\text { technical and interpersonal skills [29-31] }\end{array}$ & $\begin{array}{l}\text { Improving productivity through } \\
\text { reengineering the business } \\
\text { processes and facilitating change. }\end{array}$ \\
\hline Systems Provider & $\begin{array}{l}\text {...aims to fulfil the needs of the business; } \\
\text { limited presence in business (reactive); } \\
\text { technical skills [20, 29-32] }\end{array}$ & $\begin{array}{l}\text { Lowering the firm's operating costs } \\
\text { by reducing the cost of IT } \\
\text { operations and selecting IT projects } \\
\text { that minimize costs. }\end{array}$ \\
\hline Architecture Builder & $\begin{array}{l}\text {...aims to build and manage an IT } \\
\text { infrastructure that supports business } \\
\text { processes and reduces architectural } \\
\text { complexity; limited presence in business; } \\
\text { technical skills and industry knowledge [20, } \\
29,31,33]\end{array}$ & $\begin{array}{l}\text { Reducing architectural complexity } \\
\text { in order to increase business } \\
\text { agility. }\end{array}$ \\
\hline Technological Leader & $\begin{array}{l}\text {...aims to identify new business opportunities } \\
\text { through IT; strong CEO-CIO relationship, } \\
\text { ongoing presence in business (proactive); } \\
\text { technical, business and interpersonal skills, } \\
\text { industry knowledge [33-35] }\end{array}$ & $\begin{array}{l}\text { Implementing emerging } \\
\text { technologies with high strategic } \\
\text { potential. }\end{array}$ \\
\hline Project Coordinator & $\begin{array}{l}\text {...aims to give the organization greater } \\
\text { flexibility; strong and ongoing presence in } \\
\text { business (reactive); technical, negotiation and } \\
\text { interpersonal skills }[29,32,33,36]\end{array}$ & $\begin{array}{l}\text { Introducing a flexible and efficient } \\
\text { sourcing strategy and improving } \\
\text { the business ability to make better } \\
\text { decisions regarding IT. }\end{array}$ \\
\hline
\end{tabular}


Table 2. IT business value domains

\begin{tabular}{|l|l|l|}
\hline IT business value domain & Contribution of the IT function in this domain & Sources \\
\hline Analysis and decision support & $\begin{array}{l}\ldots \text { increases a firm's ability of prudent decision making by } \\
\text { providing valuable and detailed information. }\end{array}$ & {$[2]$} \\
\hline $\begin{array}{l}\text { Operational efficiency and } \\
\text { integration }\end{array}$ & $\begin{array}{l}\ldots \text { enables a firm to improve the productivity of its day-to-day } \\
\text { business operations by fostering internal integration and } \\
\text { facilitating communication, coordination and knowledge } \\
\text { transfer. }\end{array}$ & $\begin{array}{l}{[4][6,7],} \\
{[8,9],[10]}\end{array}$ \\
\hline Operational flexibility & $\begin{array}{l}\ldots \text { enables a firm to the quickly adaption of planned and } \\
\text { unanticipated changes. }\end{array}$ & {$[11]$} \\
\hline External integration & $\begin{array}{l}\ldots \text { increases a firm's ability to coordinate supplier linkages } \\
\text { and monitor supply chains. }\end{array}$ & {$[11]$} \\
\hline $\begin{array}{l}\text { Market access and innovation } \\
\text { support }\end{array}$ & $\begin{array}{l}\ldots \text { increases a firm's ability to enter new markets, introduce } \\
\text { and innovate new products or services and facilitate business } \\
\text { process innovation. }\end{array}$ & {$[13]$} \\
\hline Risk and compliance & $\begin{array}{l}\ldots \text { enables a firm to improve risk-handling as well as } \\
\text { submission to internal policies and external regulations. }\end{array}$ & {$[15]$} \\
\hline
\end{tabular}

sources of value from IT, we refer them as IT business value domains.

So far, it is not known if there is any connection between ITMP and IT business value domain but our aim is to find out if there exist one or more connections. Based on the assumptions of [1] we propose that -dependent on its ITMP- an IT function does not equally contribute to the organizations performance in all six IT business value domains, but in minimum one or just a few.

Subsequently, we put forth the following hypothesis:

(H) Each IT management profile contributes to minimum one IT business value domain, and so, forms an unique IT business value profile.

\section{Research method}

In the following section we present our research method and how we collected and analysed our data with regard to our research question.

\subsection{Data collection}

In order to answer the research questions, we conducted a quantitative study with IT and business executives (CIO/CEO). We decided to carry out a quantitative study and not a qualitative approach, because there exist too many possibilities of connections between ITMPs and IT business value domains. Therefore, a qualitative research approach was not suitable. To that end, we requested the CIO of a firm to name the CEO, or a general manager, or a business executive of the firm to verify the ITMP that is implemented. Moreover, we intended to ask the actual involvement of IT to the IT business value domains.

For that purpose, we developed a measurement instrument for the CIO to evaluate the perceptions on the actual ITMP of the IT function and we asked general information about the firm (e.g. number of IT employees, IT outsourcing proportion, industry sector, etc.). Therefore, the CIO had to assess ITMP related questions (example question for Technology Leader profile: most of our IT activities focused on new technologies or research results to develop modern applications).

Moreover, we asked the business executive (CEO) to assess which IT business value profiles are critical for realizing their work. As to that, we asked the CEO to prioritize the IT business value domains according to their importance for their work. For the assessment of the actual involvement of the IT function to the IT business value domains, slightly adapted items from prior research were used (see Table 2). The business executives were asked in the questionnaire to prioritize the IT business value domains according to their relevance for their work. Each business executive had to allocate 100 points to a maximum of four IT business value domains.

The questionnaire concerning the CIO encompassed a set of self-developed items that aimed to capture the ITMP implemented by the CIO. This instrument followed upon the multiple measured approach as proposed by [37]. For validating the 
newly-developed and adapted measurement items, we applied the guideline of [38].

The development procedure comprises the stages conceptualization, development of measure, model specification, scale evaluation and refinement, validation, and norm development. Moreover, we pre-tested both measurement instrument with CIOs and associated scholars.

The survey was conducted across firms within the manufacturing industry in Germany. The firms have been identified using the firm database of Bisnode [39] that comprises significantly companies with 100 to 10,000 employees from different sectors. For the present research we use data of production; energy; construction; trade, maintenance, and repair of motor vehicles; transportation and storage; provision of professional, scientific, and technical services; and provision of other business services. Within the Bisnode database top or middle level managers for IT are recorded. The initial sample comprises 1,120 firms. We used the general contact information provided by the Bisnode database to contact each firm by phone or e-mail, explain our interest and ask for the contact information of an IT department responsible manager and an equivalent business manager. We excluded companies that not wish to participate or were not available. Hence, contact data of a random sample of 736 IT managers were collected. Then we sent an online-based survey via email to the managers. The cover letter explained our interests, provided the link to the survey and contained a request to forward the link directing to the business specific questionnaire to a senior management executive of the firm's strategic level, respectively. This way, we aimed to ensure to have a matched-pair dataset (one answer from $\mathrm{CIO}$ and the other one from CEO, both are from the same company) for each case for our analyses.

Data collection took place during a period of two months (March to April 2015). In total, we collected 146 responses, whereby 30 data sets revealed missing values. Moreover, 10 responses needed to be excluded since either the CIO or the business executive did not answer the questionnaire. The final sample comprises 106 complete responses, reflecting 53 matched-pairs (53 answers from CIOs and 53 answers from CEOs of the same company) and a response rate of $7.2 \%$. Table 3 depicts the demographics of the collected responses.

Table 3. Demographics of our data sample ( $n=53$ firms)

\begin{tabular}{|l|l|r|r|}
\hline & & Firms & Share \% \\
\hline Sector & Glass / Plastic & 4 & 7.5 \\
\hline
\end{tabular}

\begin{tabular}{|l|l|r|r|}
\hline \multirow{5}{*}{} & Automotive & 4 & 7.5 \\
\cline { 2 - 4 } $\begin{array}{l}\text { Engineering / } \\
\text { Aerospace / } \\
\text { Shipbuilding }\end{array}$ & 19 & 36.0 \\
\cline { 2 - 4 } & Chemical & 2 & \\
\cline { 2 - 4 } & Pharmaceutical & 2 & 4.0 \\
\cline { 2 - 4 } & Textile & 3 & 6.0 \\
\cline { 2 - 4 } & Electricity & 9 & 17.0 \\
\cline { 2 - 4 } & Nutrition & 5 & 9.0 \\
\cline { 2 - 4 } & Other & 5 & 9.0 \\
\hline \multirow{5}{*}{ Turnover } & $10-50$ m. EUR & 7 & 13.0 \\
\cline { 2 - 4 } & $51-250 \mathrm{~m}$. EUR & 12 & 23.0 \\
\cline { 2 - 4 } & $251-500 \mathrm{~m} . \mathrm{EUR}$ & 12 & 23.0 \\
\cline { 2 - 4 } & $>501 \mathrm{~m} . \mathrm{EUR}$ & 22 & 41.0 \\
\hline \multirow{5}{*}{ Employee } & 250 & 8 & 15.1 \\
\cline { 2 - 4 } & $251-1,000$ & 15 & 28.3 \\
\cline { 2 - 4 } & $1,001-5,000$ & 25 & 47.2 \\
\cline { 2 - 4 } & $5,001-10,000$ & 5 & 9.4 \\
\hline
\end{tabular}

\subsection{Data analysis}

To assess which of the ITMP the CIO has most likely adopted, a profile deviation approach was followed. Moreover, we calculated scores that reflect the actual and the required contributions on each IT business value domain. Finally, we calculated Pearson correlations [40] between ITMP membership-scores and the scores reflecting actual contributions to the IT business value domains. Below we explicate the methods that we applied to get input data for the correlation analysis in greater detail.

To calculate the ITMP deviation we use the following approach. We analysed five measurementitems reflecting distinct dimension of the ITMP. Each answer reflects characteristics of one or more ITMP. In summary five questions concerning management profiles (MP1-MP5) with five possible answer options (MP1.1-MP1.5, etc.) had to be answered by the CIO. Accordingly, the answers were assigned with scores for every ITMP. For instance, if the CIO reported that important IT investment decision are made in close cooperation between business units and IT, scores have been assigned to the partner profile. The first and second questions were necessary for a percentage allocation and with the help of the remaining questions, a direct allocation to an ITMP was possible. All answer options of the questions were assigned to minimum one ideal ITMP. 
Afterwards it was proven which answers were applicable for which ITMP. Each response that was consistent with the management profile was rated with maximum 1. Answers to the questions MP1 and MP2 were assessed with value percentage ( values between 0 and 1). Answers to the questions MP3, MP4, and MP5 were rated with either 0 (not true) or 1 (true). An example for a formula in case of the Partner profile for this described process is:

Partner(Firm B $)=($ MP1.1 + MP2.1 + (if MP3.1 $=$ 1 then 1 else 0$)+($ if MP4. $1=1$ then 1 else 0$)+($ if MP5.1 = 1 then 1 else 0$)) / 5$

The realized scores for each ideal management profile have then be set in relation to the maximum scores (100 percent) achievable. The value of the quotient reflects an IT function's membership of each ITMP (i.e. its profile deviation), such that the higher the quotient, the lower the deviation. When we take the calculation formula again, as an example Firm B has achieved the following scores for the Partner profile:

Partner(Firm B $)=(0,5+0,7+0+1+1) / 5=0,64$ Firm B met 64 percent of the Partner profile.

Scores for the importance of each IT business value domain were calculated as follows. For each option the business executive could allocate points which are associated with a distinct IT business value domain. We arithmetically averaged business executives' allocation of points to the IT business value domains and calculated the distribution of points on a percentage basis. These scores reflect the significance of each IT business value domain for ITMPs.

Data on the actual contribution of the IT function to the IT business value domains were collected using multiple Likert-scaled items for each domain. To ensure that the items significantly load on their related IT business value, a principal component analysis (PCA) was conducted, to analyse interrelations between the set of variables [41]. PCA revealed six distinct factors with eigenvalues greater than 1.0. Moreover, all items loaded significantly above 0.7 on their related factors.

Therefore, validity of the distinctiveness of the hypothesized IT business value domains and their related items is indicated.

\section{Findings}

The following section presents our findings. Data analysis provides some evidence for our hypothesis. Data reveals that every ITMP is related to at least one IT business value domain.

Table 4 shows the results of the correlation analysis concerning the ITMP memberships and the IT function's actual contribution to the proposed IT business value domains [40]. Positive correlation between profile membership and IT business value domain indicate that the ITMP delivers a contribution to the IT business value domain, negative correlation rather show that the membership to the ideal ITMP is negatively related to this domain. Significant coefficient-values exceeding the threshold of .1 indicate 'small effects', values exceeding .3 'medium effects' and values exceeding .5 'large effects'[42]. As depicted in Table 4 almost all significant effects exceed the threshold of .3 , hence indicating medium effects.

For example, the results regarding the ideal partner profile can be interpreted as follows. The closer an IT functions' management approach is to

Table 4. Pearson correlations coefficients (IT management profiles - IT business value domain)

\begin{tabular}{|l|c|c|c|c|c|}
\hline \multirow{2}{*}{ IT business value domains } & \multicolumn{4}{l|}{ IT management profiles } \\
\cline { 2 - 6 } & Partner & $\begin{array}{c}\text { System } \\
\text { Provider }\end{array}$ & $\begin{array}{c}\text { Architecture } \\
\text { Builder }\end{array}$ & $\begin{array}{c}\text { Technological } \\
\text { Leader }\end{array}$ & $\begin{array}{c}\text { Project } \\
\text { Coordinator }\end{array}$ \\
\hline External integration & $\mathbf{- 0 . 3 5 7}^{* *}$ & 0.163 & 0.260 & -0.233 & $\mathbf{0 . 4 3 5}^{* *}$ \\
\hline Risk and compliance & -0.156 & $\mathbf{0 . 3 1 9}^{*}$ & -0.114 & $\mathbf{0 . 2 9 9}^{*}$ & -0.087 \\
\hline Market access and innovation support & $\mathbf{0 . 4 0 5}^{* *}$ & $\mathbf{- 0 . 4 3 6}^{* *}$ & -0.251 & 0.163 & $\mathbf{- 0 . 4 8 5}^{* *}$ \\
\hline Operational efficiency and integration & -0.224 & 0.072 & $\mathbf{0 . 3 9 5}^{* *}$ & -0.185 & -0.269 \\
\hline Operational flexibility & 0.135 & $\mathbf{- 0 . 2 9 2}^{*}$ & -0.129 & 0.115 & -0.006 \\
\hline Analysis and decision support & $\mathbf{0 . 4 2 0}^{* *}$ & $\mathbf{- 0 . 3 0 0}^{*}$ & $\mathbf{- 0 . 4 1 9}^{* *}$ & -0.069 & -0.052 \\
\hline $\begin{array}{l}* *=\text { correlation is high significant }(\mathrm{p} \leq 0.001) \\
*=\text { correlation is significant }(\mathrm{p} \leq 0.01)\end{array}$ & & & & \\
\hline
\end{tabular}


the Partner profile, the more likely the IT function contributes to enhancements regarding market access and innovation capability (see Table 4 value $\left.0.405^{* *}\right)$. Moreover, the more likely IT enables and improves analysis and decision support. On the other hand, closeness to the Partner profile is significantly related to a low probability of strong contributions to the external integration of the firm. No significant effects between the proximity to the Partner profile and other IT business value domains are found.

Considering the Systems Provider profile, findings reveals that membership correlates significantly with distinct contributions of IT to firm's ability to improve risk-handling and to comply with internal policies and external regulations (i.e. risk and compliance). Moreover, we found significant negative correlations between the closeness of the adopted management approach to the System Provider profile and the IT business value domains market access and innovation support, operational flexibility as well as analysis and decision support. Hence, evidence is given that the more an IT functions' management approach equals the System Provider profile, the less likely the IT offers a significant contribution to the mentioned domains.

Data further reveal a medium effect between an IT functions proximity to the ideal profile Architecture Builder and significant contributions of IT to operational efficiency and integration. Hence, evidence is given that IT functions focusing on the development of external efficiency and integration are more likely to enable business to improve the productivity of their day-to-day operations. Like IT functions close to the Systems Provider archetype, IT functions that reveal high membership scores to the Technological Leader profile more likely provide distinct contributions to firms' ability to improve risk-handling and to comply with internal policies and external regulations (i.e. risk and compliance) than any other profiles. However, the Technological Leader profile is not significantly related to contributions in other IT business value domains.

Last not least, data reveals that IT functions which are close to the Project Coordinator archetype are significantly correlated with distinct contributions to a firm's ability to coordinate supplier linkages and monitor supply chains (i.e. external integration). The closer an IT management approach is to the Project Coordinator archetype, the less likely it enables a firm's ability to enter new markets, introduce and innovate new products or services and facilitate business process innovation.

\section{Discussion}

Before we discuss our findings, we acknowledge the limitations of this study. First of all, it needs to be recognized that the scope of our survey limits the generalizability of the findings. Our analysis draws on data that was collected in a single sector and only encompasses firms of one country. We recommend to expand the study to other industries and collect data within different countries to gain a representative study. Such studies may increase confidence in our findings. Second, to capture those IT contributions that create value for a firm more nuanced, the measurement instruments employed to collect data on required contributions of IT might be optimized, so as to that it captures business need with greater granularity. Third, we would recommend to conduct a qualitative study to gain more information about the research field and the constellations of ITMPs and IT business value domains in detail.

\subsection{IT management profiles provide IT business value}

With the present research, we made a refinement and extension of the "new theory of the contribution of the IT function in organizations". Motivated by the call of Guillemette and Pare [1], we deliver a further validation in a new sample of organizations by means of a quantitative research approach. As to that, our research provides some evidence that the ideal IT management profiles contribute to organizational performance by means of providing value in distinct domains. Below we discuss how the characteristics of the profiles and their contributions are related.

The Partner profile aims at fostering organizational transformation and innovation by maintaining fruitful relationships to its business units [1]. Therefore, it is somehow intuitive that the Partner profile shows a high and significant correlation with contributions to market access and innovation support as well as to analysis and decision support. The ability to enter new markets, introduce innovation and transform business activities by implementing business process innovation which is consistent with [29]. Our findings present evidence, that the IT can support innovative ideas and strategies, as well as supporting different market strategy. Through the high correlation between the Partner profile and analysis and decision making processes, findings indicates that the Partner profile enables effective coordination between functional areas. If decisions have to be made, IT supports these processes, which could be particularly helpful in 
strategic environments [2]. The contributions of the IT function are, thus, well aligned with the objectives of the organisation.

Considering the Systems Provider profile, our study indicates that IT functions adopting this profile particularly contributes to effective risk and compliance management. Particularly, this link might be helpful in daily business and therefore gains value for business. Systems Providers seem to facilitate risk-handling in their daily business by developing and implementing reliable and regulation-conform IT applications and efficient and effective business processes, which are requested by the business-side [1, 15, 31]. Spanaki and Papazafeiropoulou [15] described in their research that the implementation of risk and compliance, for instance delivers a positive influence on operational performance. Hence, the establishment of the ITMP of the System Provider might positively influence operational performance.

Equally, Architecture Builders' contribution seem to be well aligned with their management approach. Data reveals that they primarily contribute to operational efficiency and integration, which might be enabled by reducing complexity and developing an integrated and flexible architecture [29]. The Architecture Builder might focus on controlling products and transitions costs [4], this is suitable with the ability of reducing architectural complexity. Improving operational efficiency through IT further requires technical skills and industry knowledge two distinctive characteristics of this management profile.

While the contributions of the Architecture Builder focuses on operational integration, the Project Coordinator seems to contribute to external integration. They have the ability of an organization to primarily coordinate supplier linkages and monitor supply chains $[1,29]$. To achieve contributions in this domain, the management focuses on the development of technical, negotiation and interpersonal skills to foster cooperation. These skills enable IT staff to cooperate with internal and external parties and hence, promote external integration, e.g. by coordinating IT projects in a high outsourcing environment. The high significant value between Project Coordinator and external integration implicate a focus on market scanning and competitive activities [4]. This is compatible with the results of [1].

However, the correlations between the proximities to the Technological Leader profile and contributions to the IT business value domains is somehow counterintuitive. Data reveals that IT functions adopting a Technological Leader style are significantly positive correlated with distinct contributions to a firm's ability to deal with risk and compliance issues. However, since this profile aims at experimenting with new IT and implementing novel IT applications, it is hard to find explanations for this effect. One may have expected that IT functions close to this profile will contribute to a firm's ability to enter markets and introduce innovation as well as facilitating operational flexibility. Although these correlations are positive, they were not found to be significant. On the other hand, contributions to risk and compliance may be caused by the strategic relevance of novel technology in order to identify new business opportunities. Here, organizations have to put a strong focus on balancing risks associated with novel technology. Furthermore, IT could be used to deal with compliance requirements or to reduce risks and it could be possible that requirements places demands regarding the effectiveness of IT. However, further research may dig deeper into this issue. Particularly qualitative studies may provide explanations for this effect.

Overall our findings provide support for the proposition of [1] that the contribution of IT is dependent on its management profile. Moreover, our study does characterize these contributions in greater detail and, as we argue in the following sections, enable us to link ITMP to competitive strategy. Ultimately, this enables CEOs and CIOs to improve cross-domain alignment.

\subsection{Evidence for cross-domain alignment}

Providing evidence for cross-domain alignment, our data reveals that each ITMP corresponds with at least one IT business value domain to build an IT business value profile.

IT functions that adopted the Systems Provider or the Technological Leader profile most likely provide significant contributions to the IT business value domain of risk and compliance. An IT function which is following this management profile, is oriented towards supplying systems that are required by business. Therefore, activities mainly focus on developing or acquiring and implementing IT applications. Making investments decisions is solely up to the business. Hence, IT is rather expected to contribute to the management of operational risks than enabling or enhancing operational processes (i.e. increase efficiency and flexibility or enable innovation and growth).

In contrast, the Partner profile enables an IT function to be an active partner in business transformation and innovation. The Partner aims at reengineering business processes and implementing IT applications that enable innovation and growth. 
Hence, the relation with the business units and external partners is characterized by strong and ongoing IT presence in business units. Providing IT applications and services that increases a firm's ability to enter new markets and innovate products requires strong relationships between business and IT, for instance reflected by shared responsibility for investments and project success.

In addition, considering operational efficiency and integration as link to ITMP, we found that the Architecture Builder deliver this. Operational efficiency and integration empowers firms to enhance productivity of their operational business as well as to improve internal communication and knowledge management. Architecture Builder contribute to this domain by reducing complexity within the IT architecture, which facilitates operational efficiency.

Our data does not provide evidence that any ITMP delivers distinct contributions regarding flexibility. This may be attributed to our sample size and the type of industry. Within the manufacturing sector, flexibility is most likely much more dependent on capital intensive facilities than on IT.

However, the study at hand provides early evidence that IT business value domains are capable with ITMP. Further research should further investigate this phenomenon. Particularly, they may investigate if and how cross-domain alignment between ITMP and IT business value domains contributes to firms' business value.

\section{Conclusion}

This paper examines if ideal ITMPs provide distinctive contributions to an organization. As to that, we derive six IT business value domains from prior literature and propose that these domains deliver a distinctive source of value to the organization. Building upon these considerations, we hypothesize that each ITMP provides distinctive contributions to a limited set of these domains. Results of our quantitative study provide some evidence that business IT value domains do indeed link ITMPs.

The findings of this study offer some important implications for research and practice. First, this research extends the theory of the contribution of the IT function [1]. As to that, the study confirms prior research and increases confidence in the applicability of the idealized ITMPs proposed by [1]. In addition, we shed light on the contributions of each profile and showed empirically that each management profile is associated with a distinct contribution by means of a combination of IT business value domains. As to that, this study increases our understanding on the nature of these contributions. The proposed IT business value domains reflect how contribution of each ITMPs more tangible.

Considering practical implications, this study motivates IT executives to assess the ITMP they are close to. Depended on the ITMP the IT function is able to contribute significantly to one or more IT business value domain and hence, provide an advantage for the organization. We deliver a research that help in practice to constitute the right ITMP to pursue the desired business orientation through contribute to one or more IT business value domains. This study helps CIOs to strengthen and organize their IT function and gives implications about how they can influence business by adopting a certain ITMP.

\section{Acknowledgement}

We would like to thank Daniel Hackenberg for his support during the data collection phase.

\section{References}

[1] Guillemette, M.G., and Pare, G., "Toward a New Theory of the Contribution of the IT Function in Organizations", MIS Quarterly, 36(2), 2012, pp. 529-551.

[2] Venkatraman, N., "Strategic Orientation of Business Enterprises: The Construct, Dimensionality, and Measurement", Management Science, 35(8), 1989, pp. 942962.

[3] Gerow, J.E., Thatcher, J.B., and Grover, V., "Six Types of IT-Business Strategic Alignment: An Investigation of the Constructs and Their Measurement", European Journal of Information Systems, 24(5), 2015, pp. 465-491.

[4] Mclaren, T., Head, M., and Yuan, Y., "Strategic Fit of Supply Chain Management Information Systems: A Measurement Model", International Conference of Information Systems, 2004.

[5] Chan, Y.E., and Reich, B.H., "IT Alignment: What Have We Learned?", Journal of Information Technology, 22(4), 2007, pp. 297-315.

[6] Ravichandran, T., and Lertwongsatien, C., "Effect of Information Systems Resources and Capabilities on Firm Performance: A Resource-Based Perspective", Journal of Management Information Systems, 21(4), 2005, pp. 237276.

[7] Sabherwal, R., Hirschheim, R., and Goles, T., "The Dynamics of Alignment: Insights from a Punctuated Equilibrium Model", Organization Science, 12(2), 2001, pp. 179-197.

[8] Bradley, R.P., Pridmore, J.L., Byrd, T.A., "Information Systems Success in the Context of Different Corporate Cultural Types: An Empirical Investigation", Journal of Management Information Systems, 23(2), 2006, pp. 267294.

[9] Wade, M., and Hulland, J., "Review: The ResourceBased View and Information Systems Research: Review, 
Extension, and Suggestions for Future Research", MIS Quarterly, 28(1), 2004, pp. 107-142.

[10] Mitchell, V.L., "Knowledge Integration and Information Technology Project Performance", MIS Quarterly, 30(4), 2006, pp. 919-939.

[11] Mclaren, T., Yuan, Y., Head, M., and Head, M.M., "Strategic Fit of Supply Chain Management Information Systems: A Measurement Model", International Conference on Information Systems, 2004, pp. 12-15.

[12] Peppard, J., and Ward, J., "Beyond Strategic Information Systems: Towards an IS Capability", The Journal of Strategic Information Systems, 13(2), 2004, pp. 167-194.

[13] Wang, N., Liang, H., Zhong, W., Xue, Y., and Xiao, J., "Resource Structuring or Capability Building? An Empirical Study of the Business Value of Information Technology", Journal of Management Information Systems, 29(2), 2012, pp. 325-367.

[14] Schryen, G., "Revisiting IS Business Value Research: What We Already Know, What We Still Need to Know, and How We Can Get There", European Journal of Information Systems, 22(2), 2013, pp. 139-169.

[15] Spanaki, K., and Papazafeiropoulou, A., "Analysing the Governance, Risk and Compliance (Grc) Implementation Process: Primary Insights", European Conference on Information Systems, 2013.

[16] http://www.gartner.com/newsroom/id/3084817, accessed 14.06.2016.

[17] Santhanam, R., and Hartono, E., "Issues in Linking Information Technology Capability to Firm Performance", MIS Quarterly, 27(1), 2003, pp. 125-153.

[18] Kohli, R., and Grover, V., "Business Value of IT: An Essay on Expanding Research Directions to Keep up with the Times", Journal of the Association for Information Systems, 9(1), 2008, pp. 23-39.

[19] Melville, N., Kraemer, K., and Gurbaxani, V., "Review: Information Technology and Organizational Performance: An Integrative Model of IT Business Value", MIS Quarterly, 28(2), 2004, pp. 283-322.

[20] Cross, J., Earl, M.J., and Sampler, J.L., "Transformation of the IT Function at British Petroleum", MIS Quarterly, 21(4), 1997, pp. 401-423.

[21] Guillemette, M., and Pare, G., "Understanding the Role and Transformation of the Information Technology Function in Organizations", International Conference on Information Systems, 2005.

[22] Armstrong, C.P., and Sambamurthy, V., "Information Technology Assimilation in Firms: The Influence of Senior Leadership and IT Infrastructures", Information Systems Research, 10(4), 1999, pp. 304-327.

[23] Preston, D.S., and Karahanna, E., "Antecedents of IS Strategic Alignment: A Nomological Network", Information Systems Research, 20(2), 2009, pp. 159-179.

[24] Tallon, P.P., and Kraemer, K.L., "Fact or Fiction? A Sensemaking Perspective on the Reality Behind Executives' Perceptions of IT Business Value", Journal of Management Information Systems, 24(1), 2007, pp. 13-54. [25] Henderson, J.C., and Venkatraman, N., "Strategic Alignment: Leveraging Information Technology for Transforming Organizations", IBM Systems Journal, 32(1), 1993, pp. 4-16.
[26] Henderson, J.C., and Venkatraman, N., "Strategic Alignment: Leveraging Information Technology for Transforming Organizations", IBM Systems Journal, 38(2/3), 1999, pp. 472-484.

[27] Jordan, E., and Tricker, B., "Information Strategy: Alignment with Organization Structure", The Journal of Strategic Information Systems, 4(4), 1995, pp. 357-382.

[28] Ross, J.W., Beath, C.M., and Goodhue, D.L., "Develop Long-Term Competitiveness through IT Assets", MIT Sloan Management Review, 38(1), 1996, pp. 31.

[29] Brown, C.V., and Mclean, E.R., "Partnering Roles of the IS Executive", Information Systems Management, 13(2), 1996, pp. 14.

[30] Clark, C.E., Cavanaugh, N.C., Brown, C.V., and Sambamurthy, V., "Building Change-Readiness Capabilities in the IS Organization: Insights from the Bell Atlantic Experience", MIS Quarterly, 21(4), 1997, pp. 425455.

[31] Ross, J.W., "Creating a Strategic IT Architecture Competency: Learning in Stages", MIS Quarterly Executive, 2(1), 2003, pp. 31-43.

[32] Peppard, J., and Ward, J., "'Mind the Gap': Diagnosing the Relationship between the IT Organisation and the Rest of the Business", The Journal of Strategic Information Systems, 8(1), 1999, pp. 29-60.

[33] Agarwal, R., and Sambamurthy, V., "Principles and Models for Organizing the IT Function", MIS Quarterly Executive, 1(1), 2002, pp. 1-16.

[34] Reich, B.H., and Nelson, K.M., "In Their Own Words: Cio Visions About the Future of in-House IT Organizations", ACM SIGMIS Database, 34(4), 2003, pp. 28-44.

[35] Curley, M., "The IT Transformation at Intel", MIS Quarterly Executive, 5(4), 2006, pp. 155-168.

[36] Feeny, D., and Willcocks, L., "Core IS Capabilities for Exploiting Information Technology", MIT Sloan Management Review, 39(3), 1998, pp. 9-21.

[37] Conant, J.S., Mokwa, M.P., and Varadarajan, P.R., "Strategic Types, Distinctive Marketing Competencies and Organizational Performance: A Multiple Measures-Based Study", Strategic Management Journal, 11(5), 1990, pp. 365-383.

[38] Mackenzie, S.B., Podsakoff, P.M., and Podsakoff, N.P., "Construct Measurement and Validation Procedures in Mis and Behavioral Research: Integrating New and Existing Techniques", MIS Quarterly, 35(2), 2011, pp. 293334.

[39] http://www.hoppenstedt-hochschuldatenbank.de/, 14.04.2014.

[40] Bollen, K.A., and Barb, K.H., "Pearson's R and Coarsely Categorized Measures", American Sociological Review, 1981, pp. 232-239.

[41] Straub, D., Boudreau, M.-C., and Gefen, D., "Validation Guidelines for IS Positivist Research", The Communications of the Association for Information Systems, 13(1), 2004, pp. 63.

[42] Chin, W.W., "The Partial Least Squares Approach to Structural Equation Modeling", Modern Methods for Business Research, 295(2), 1998, pp. 295-336. 